The Research Journal of the Costume Culture

[Original Article]
Received April 18, 2017

Revised June 12, 2017

Accepted June 22, 2017

${ }^{\dagger}$ Corresponding author

(ysyoo@khu.ac.kr)

ORCID

Youngsun Yoo

http://orcid.org/0000-0001-6158-0860

This paper is a part of a master's thesis.

\section{A study on design methods and expressional characteristics of papercraft fashion}

\author{
Ming Zhe Hou and Youngsun $\mathrm{Yoo}^{\dagger}$ \\ Dept. of Clothing \& Textiles, Kyung Hee University, Korea
}

\begin{abstract}
The purpose of this study is to investigate the design methods and characteristics of papercraft fashion from 2001 to 2015 . The study has been conducted through theoretical research and case study. Overall, types of papercraft expressions are classified into the following four categories: narrative papercraft fashion, organic papercraft fashion, variable papercraft fashion, and recycling papercraft fashion. The characteristics and aspects of each type of papercraft is described below. First, narrative papercraft fashion expresses as factual description of the natural environment. These works convey fantastic image by showing fairy tale animals or plants using paper folding or cutting. Second, organic papercraft fashion creates a futuristic shape by expressing organic parts in nature. Also, it often depicts future-oriented images by repeatedly representing organic shapes using uniform patterns in nature. Third, variable papercraft fashion expresses a variety of changing shapes through a flexible design based on the style of wearing. This variation may be accomplished through changeable dress connected to human gestures. Variable papercraft represents playfulness, which conveys enjoyment to the wearer and the audience. Fourth, recycling papercraft fashion uses paper materials of the past, and recreates them into artworks through handicraft techniques. Recycling papercraft conveys high value added fashion by dissolving the material into pulp.
\end{abstract}

Keywords: papercraft(종이 공예), narrative papercraft fashion(내러티브 페이퍼크라프 트), organic papercraft fashion(오가닉 페이퍼크라프트), variable papercraft fashion(가변적 페이퍼크라프트), recycling papercraft fashion(리사이클링 페이퍼크라프트)

\section{Introduction}

오늘날 급속한 속도로 발전하고 있는 디지털환경은 인간생활의 편리함을 가져 왔으며, 디자인 분야에서도 첨단적 디자인 방식과 미래적 기술 발전이 예고되고 있 다. 반면, 디지털 기술 중심의 문화 발전에서 도래된 삶의 변화로 인해 인간에게 정 
신적인 위로와 향수를 채워줄 수 있는 아날로그 감성 의 디자인에 대한 관심이 증대하고 있다. 패션분야에 서도 이러한 경향은 트렌드로 반영되어 인간의 서정 성을 조화시킨 섬세한 디테일과 미학적 가치를 담은 아날로그 감성의 디자인 가치가 강조되고 있다.

페이퍼크라프트는 디지털 시대의 인간적 서정성을 표현할 수 있는 아날로그적 기법으로 종이의 자연적 소재 특성과 수작업으로 이루어지는 공예성은 인간 친화적인 감성을 표현 가능하게 하였다. 종이는 20세 기 초 꼴라주, 앗상블라주 등 현대 조형예술의 작가 적 메시지 전달의 표현매체로 사용되면서 예술 표현 영역의 확대와 함께 전통적 재료 사용에 대한 새로운 시각을 제시하였다.

현대 패션에서의 종이의상은 1960년대 미국의 Scott Paper Company의 마케팅 홍보물로 등장하였는데, 일 회용 재료로 만들어졌다(“Paper clothing”, n.d.).

패션디자이너의 컬렉션에서 페이퍼크라프트의 사 용은 2011, 12년 FW ISSEY MIYAKE 컬렉션에서 나 타났다. ISSEY MIYAKE 크리에티브 디렉터인 Dai Fujihara는 이 컬렉션에서 페이퍼크라프트 기법 중 하 나인 접기 방식의 오리가미와 종이를 사용하여 다섯 벌의 종이조형을 선보이는 패션 퍼포먼스를 통하여 디자이너의 콘셉과 창의적 이미지를 표현하였다(Bumpus, 2011).

이와 같이 페이퍼 패션의 혁신성과 페이퍼크라프 트가 가지는 수공예적 특성이 디지털시대 인간을 위 로하고자하는 패션 디자이너의 콘셉과 창의성을 표 현가능하게 하였다.

이러한 배경으로 본 연구에서는 페이퍼크라프트의 기법에서 발현되는 아날로그적 디자인 특성을 파악 하여 페이퍼크라프트 패션의 디자인 방법과 표현특 성의 새로운 가치를 탐색하고자 하였다. 특히 페이퍼 크라프트의 입체조형으로 제작된 패션작품들이 지니 고 있는 외연적 표현특징과 관련된 작가의 컨셉을 분 석함으로써 페이퍼크라프트 패션의 디자인특성을 파 악하고자 하였다.

따라서 본 연구의 목적은 페이퍼크라프트를 활용 한 패션 디자인 작품사례들을 분석하여 페이퍼크라 프트 패션의 디자인 방법과 표현 특성을 밝힘으로써 디지털 시대 인간에게 위로와 즐거움을 주는 창의적 패션디자인 개발에 도움이 되고자 하는데 있다.
연구의 방법은 예술 디자인분야에 나타난 페이퍼 크라프트 사례들을 중심으로 페이퍼크라프트의 미적 표현특성을 알아보고, 이를 근거로 페이퍼크라프트를 활용한 패션 디자인 사례들을 유형화하여 디자인 방 법을 분석하고, 표현 특성을 도출하였다. 예술 디자인 분야의 사례 수집은 2001년 이후 나타난 페이퍼 아티 스트의 작품을 중심으로 공예, 가구, 생활소품, 설치 미술, 디스플레이 분야에서 이루어졌다. 패션사례 수 집은 문헌과 '페이퍼'와 '페이퍼크라프트'의 키워드 를 활용한 웹사이트 검색을 통해 총 242장의 사진이 수집되었으며, 이 중 동일 작가의 유사한 작품사례를 제외하고, 종이로 만들어지고 전문적인 패션 디자이 너들에 의해서 작품화된 것들을 확인되어 있는 작품 들을 중심으로 최종적으로 총 130 벌의 작품을 분석에 사용하였다.

\section{Concept and Expressional Characteristics of Papercraft}

\section{Concept of papercraft}

종이는 부드러우면서도 질기고 견고하면서도 형태 변형이 쉽고 타 재료와의 혼합이 용이하다는 특징을 가지고 있다(Jung, 2004). 또한 제작 공정이 소박하고 천연 재료, 명상적 성질이 있다는 점에서 예술적 매 체의 가능성을 지니며, 손으로 종이를 만든다는 것은 자연과 역사와 전통적 용도에 관련을 맺는 것이며, 찬 란한 종이의 역사를 계승하는 일이 될 수 있다는 정 신적 가치도 지닌다(Ryu, 2007).

페이퍼크라프트(Papercraft)는 한국어로 종이조형 이다. 종이조형이란 형을 만드는 행위로 종이를 사용 하여 균형, 변화, 대비, 비례, 통일, 강조의 조형원리 와 질감, 양감, 공간, 재질, 색채, 운동감의 조형의 요 소에 입각하여 형태를 만드는 일을 말한다(Kim, 2005). 다시 말하면, 종이를 사용하여 접기(folded), 자르기 (cut)등의 기법을 통해 입체조형을 개발하는 예술형 식이며, 종이소재가 가지는 인간 친화적인 감성과 수 공예적인 예술성으로 다양한 디자인 분야에서 작가 의 독창성과 내면적 메시지 전달에 활용되고 있다.

서구의 대부분 국가에서는 페이퍼 폴딩과 동일한 의미로 오리가미를 사용하고 있다. 페이퍼 폴딩, 즉 종이접기는 중국에서 'Zhezi', 한국에서'Jong-ie-jeop- 
gi'라고 부른다(“Paper craft”, n.d.). 이것은 종이를 반 복적으로 접고 펼쳐 새로운 선이나 면이 형성하여 페 이퍼의 조형성 및 페이퍼크라프트의 구성미를 표현 하는 것이다.

오늘날 종이조형은 입체조형물로서의 창의적 기능 이 확대되면서 다양한 공예적 기법과 접목되어 독특하 고 개성 있는 디자인으로서 예술적 가치가 커지고 있 다. 또한 수작업으로 만들어지는 종이의 제작 공정은 종이가 가지는 소박하고 자연스러운 특성과 더불어 인간 친화적 감성을 지니고 있어서 개념적 가치가 강조 되는 현대 예술에서 작가의 예술적 감성과 창의적 아 이디어를 드러내는데 중요한 의미를 지닌다.

따라서 페이퍼크라프트는 종이 소재가 가지는 물 성과 내재된 정신적 가치를 지니고 다채로운 종이조 형기법으로 제작된 예술적 작품으로 그 개념을 정의 할 수 있다.

\section{Expressional characteristics of papercraft in} art and design

본 절에서는 예술디자인 분야에서의 페이퍼크라프 트 활용 사례고찰을 통하여 페이퍼크라프트의 표현 특성을 알아보았다. 예술 디자인 분야의 표현특성은 크게 디자이너의 콘셉 표현이 강조된 스토리텔링 (Storytelling), 자연형상을 단순하게 표현한 '오가닉 (Organic)', 페이퍼 폴딩 기법 특성 활용으로 나타난 '가변성(Variable)', 재료의 재생적 특성에서 비롯된 ‘리사이클링(Recycling)'으로 분류되었다.

\section{1) Storytelling}

‘스토리텔링'은 동화 같은 동물 캐릭터의 형상을 재현하거나, 대상과 주제의 섬세한 묘사, 또는 환상적 스토리를 리얼하게 표현하는 것으로 나타났다. Akira Yosizawa는 일본의 대표적인 페이퍼크라프트 예술가 이다. 그는 페이퍼크라프트를 생활아트 작품으로 끌 어올려 1983년 Hirohito국왕에 의해 일본인으로는 최 고의 영예인 'Rising Sun'의 호칭을 받았다(“Akira Yoshizawa", 2016). 〈Fig. 1〉은 하나의 종이를 자르지 않고 접어서 진짜 고릴라처럼 만든 그의 작품이다. 그는 이외에도 동물 형상을 시리즈로 한 작품들을 선 보였는데, 종이재료의 특성과 오리가미기법으로 동화 같은 동물 캐릭터를 작품화하였다.

〈Fig. 2〉는 종이 커팅 기법으로 이루어지는 전지예 술로 유명한 중국 현대작가 이민(李闽)의 '지나간다' 이다(Yifan, 2013). 그의 작품은 섬세하게 컷팅된 여 러 층의 종이로 원근감과 명암(明暗)을 표현하여 매 우 사실적인 입체감으로 그림처럼 표현대상과 주제 를 섬세하게 묘사하였다.

〈Fig. 3〉은 미국작가 Jeff Nishinaka의 작품으로 정 교함에 있어 기존의 페이퍼 컷팅에서는 볼 수 없었던 사실감을 묘사하였다. 3 차원으로 구성된 작품은 신화 적 생물의 신비로운 선에서부터 도시 풍경의 기하학 적 형태에 이르기까지 환상과 현실을 끌어들인 단색 의 작품으로 환상적인 입체 조각예술을 보여주었다 (Jeff Nishinaka Paper Sculpture, 2015).

〈Fig. 4〉는 Vally Nomidou의 종이죽 기법으로 제 작한 인체조형 작품이다. 작품 실제 사이즈는 인체와 비슷하게 제작되었는데, 종이는 인체형태의 사실적 표현을 가능하게 하였고, 더불어 종이재료가 가지는

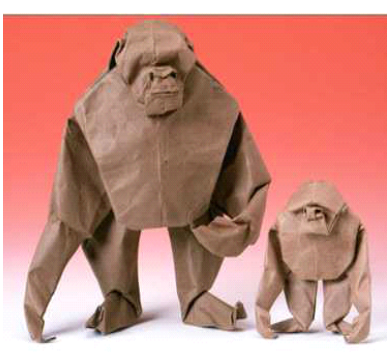

<Fig. 1> Akira Yosizawa, 2001. From. Akira Yosizawa. (2016).

http://www.barnorama.com

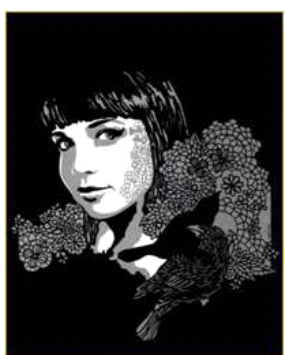

<Fig. 2> Leemin, 2003.

From. Yifan. (2013). http://blog.sina.com.cn

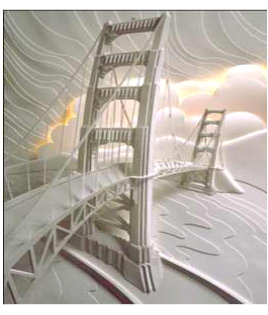

<Fig. 3> Jeff

Nishinaka, 2010.

From. Jeff

Nishinaka. (n.d.a). http://www.jeffnishi naka.com

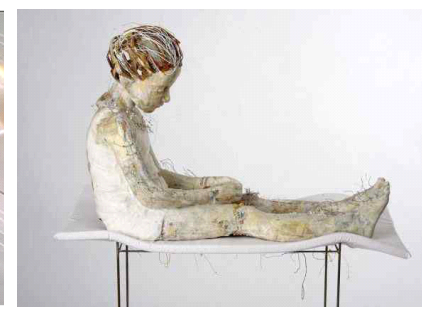

<Fig. 4> Vally Nomidou, 2012.

From. Nomidou. (2010). https://vallynomidou.wordpress. com 
연약한 이미지로 통증과 환자의 고통, 지속적인 수용 을 표현함으로써 여성적 인체가 가지는 의미를 서술 하였다(Tsikouta-Deimezi, 2011).

\section{2) Organic}

디자인 분야에서 오가닉 디자인이란 자연에 기반 을 두고 자연물의 존재원리를 모방 또는 응용하는 과 정으로 자연으로부터 유추를 통해 인위적 시스템의 발전을 기하려는 생물공학과 방법론적 접근과 다시 이러한 접근을 제어 관리하는 수단으로서 자연과의 보상적 균형관계를 통해 의미있 는 유기적인 질서를 부여하려는 생태학적 접근을 그 개념적인 모델로 삼 고 있다(Kang, 2008).

Yuko Nishimura는 손작업으로만 이루어진 페이퍼 크라프트 아트를 구현하는 작가로 여러 세대를 내려 오는 일본인들의 정서를 담은 문화와 자연친화적 형 상을 접목한 작품들을 창조하였다. 〈Fig. 5〉는 그의 종이 조각 작품 'Organic'으로 한 장의 종이를 접기 기법을 이용하여 빛과 음영으로 입체감을 나타내는 자연친화적인 오가닉 형상을 표현하였다(Klanten \& Meyer, 2011). 이 작품은 전통적인 종이접기 기법에 현대미를 더한 작품으로 평가되었다.

〈Fig. 6〉은 Richard Sweeney의 종이로 만든 조각 작품 시리즈 중 하나로 런던 'Selfridges Flagship' 매 장에 설치된 것이다(Richard Sweeney, n.d.). 이 작품 은 페이퍼 폴딩기법의 유동성을 활용하여 가변적 형 태로 만든 것이다. 〈Fig. 7〉은 Ryuji Nakamura의 작품 'Hechima 5'이며, 'Second Nature'를 주제로 하는 덴 마크와 일본 디자인 교류전(Danish-Japanese design exhibition)에 출품된 것이다. 이 전시회는 미니멀적인

이상을 지향하였는데, 그는 자연친화적인 오가닉 형 태의 종이 스툴을 제안하였다(“Second Nature", n.d.).

\section{3) Variable}

가변적(Variable)은 변할 수 있다는 뜻이며 디자인 영역에서 변형이 가능한 실험적이며 전위적인 작업 방식의 하나이다. 페이퍼크라프트의 가변적 특징은 인간친화적인 형태의 의자 소품으로 많이 나타났다.

〈Fig. 8〉은 Yoshioka Tokujin의 작품으로, 종이로 만들어진 실험적인 형태의 의자이다. '허니 팝(Honey Pop)'의 이름으로 불리는 이 의자는 벌집처럼 종이 셀 로 구성된 구조로 빛과 공기의 투과가 가능하고, 디 자이너의 앉았던 인체 흔적을 따라 컷팅된 형태였다 (“Honey-Pop chair", n.d.). 아코디언 주름과 같은 구 조는 부채모양으로 횡으로 접고 펼쳐지는 가변적 형 태를 가능하게 했는데, 펼쳐진 형태였을 때 강도가 유지되어 의자의 기능을 발휘하게 했다.

$\mathrm{Nendo}$ 사에서는 종이조형을 가구디자인 분야에서 도 활용하고 있는데, 〈Fig. 9〉'Cabbage Chair'는 Issey

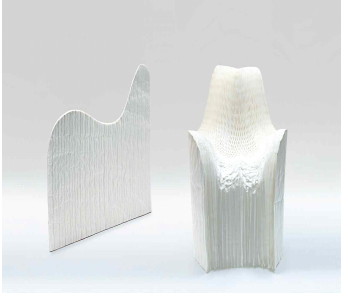

<Fig. 8> Yoshioka Tokujin, 2001. From. Honey-Pop chair. (n.d.). http://collections.vam.ac.uk

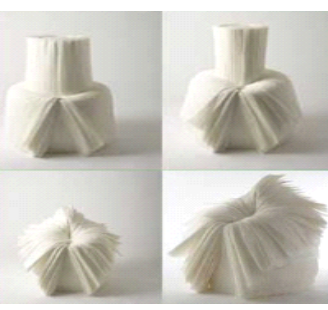

<Fig. 9> Nendo, Cabbage Chair, 2008. From.

Nendo. (2008). http://www.nendo.jp

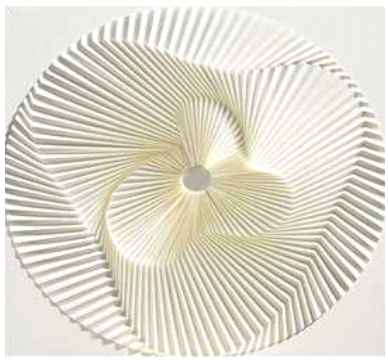

<Fig. 5> Yuko Nishimura, 2007. From. Yuko Nishimura. (n.d.). http://yukonishimura.com

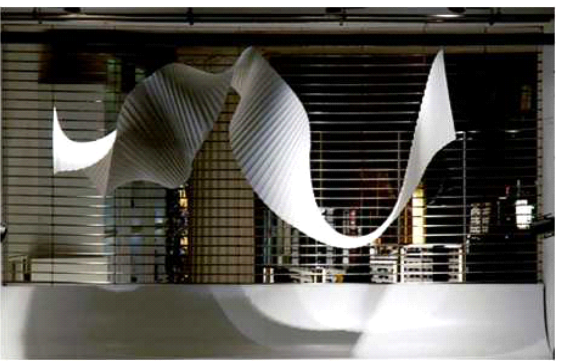

<Fig. 6> Richard Sweeney, 2008. From. Richard Sweeney. (n.d.). http://www.richardsweeney.co.uk

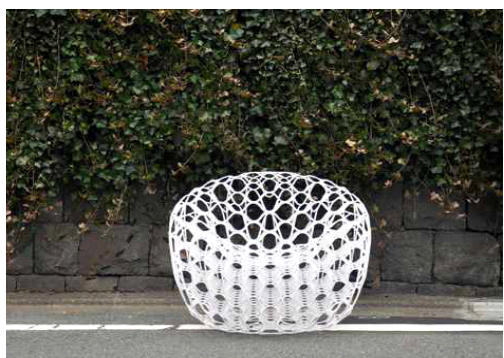

<Fig. 7> Ryuji Nakamura, 2009. From. Ryuji Nakamura. (n.d.). http://www.ryujinakamura.com 
Miyake가 기획한 도쿄에 있는 '21 21'디자인 사이트 의 1 주년을 기념하기 위해 제작한 것으로 컷팅된 면 을 한 꺼풀씩 벗겨내면 자연스럽게 앉을 수 있는 형 태로 변화 가능한 의자이다.

\section{4) Recycling}

리사이클링(recycling)의 사전적 정의는 자원을 절 약하고 환경오염을 방지하기 위하여 불용품이나 재 생하여 이용하는 것이다. 예술디자인 분야의 페이퍼 크라프트는 사용의 역사나 의미를 가진 종이재료를 재생하여 디자이너의 콘셉으로 반영되었다는 점이 특징적이었다. 〈Fig. 10〉은 Brian Dettmer의 작품 'Wagnalls Wheel'로 회전목마처럼 연결된 백과사전을 나 이프, 핀셋과 수술용 도구를 사용하여 섬세하게 컷팅 한 종이 작품이다. 오래된 책을 작가의 상상력으로 재창조된 작품으로 글자가 그림으로 변환되었다는 점에서 책을 읽거나 쓰는 의도된 기능이 아니라, 새 롭고 예기치 못한 역할인 하나의 예술품으로 새로운 의미로 제시하였다.

〈Fig. 11〉은 Rebecca Wilson의 'Paper cup project' 중 한 작품이다. Rebecca는 종이컵을 '쓰고 버리는 문 화'의 대표적 상징으로 여기고, 이것을 훌륭하고 세 련된 전통적인 도자기로 형상화하면서 낭비적인 소 비자 주의에 경종을 울리고자 하였다(Ong. 2011).

\section{Design Methods and Expressional Characteristics of Papercraft Fashion}

본 장에서는 앞장의 페이퍼크라프트 예술적 표현 특성 사례고찰에서 도출된 네 가지 특성을 근거로 페 이퍼크라프트 활용 패션작품 사례들을 유형화하고,

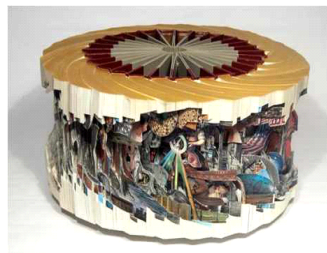

$<$ Fig. 10> Brian Dettmer, 2010. From. Brian Dettmer. (2010). http://briandettmer.com

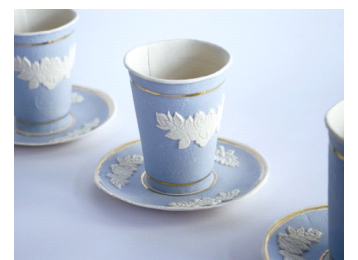

<Fig. 11> Rebecca Wilson, 2011. From. Ong. (2011). http://www.neatorama.com
각각의 표현 방법과 표현특성을 도출하였다. 즉, 예술 디자인 분야의 표현 특성인 '스토리텔링'은 디지털 스토리텔링의 표현요소인 내러티브가 패션에 중요하 게 다루어짐을 감안하여 '내러티브 페이퍼크라프트 패션'으로 유형화하였고, 뚜렷한 형태적 표현을 근거 로 하는 '오가닉'과 '가변성'은 각각 '오가닉 페이퍼 크라프트 패션'과 ‘가변적 페이퍼크라프트 패션'으로, 소재재생을 반영한 ‘리사이클링'은 ‘리사이클링 페이 퍼크라프트 패션’으로 유형화하였다.

\section{Design methods of papercraft fashion}

\section{1) Narrative papercraft fashion}

내러티브는 사전적 의미로는 '말하다'라는 뜻의 라 틴어 동사 narrare에서 유래한 단어로 스토리텔링과 유사한 의미를 가진다. 실화나 허구의 사건들을 묘사 하는 것, 그 자체뿐만 아니라 이야기를 조직하고 전 개하기 위해 이용되는 각종 전략이나 형식 등을 포괄 하는 개념이다. Yun and Yang(2004)은 내러티브를 시각과 공간에 발생하는 인과관계로 엮어진 실제 혹 은 허구적인 사건들의 연결을 의미하는 문자언어와 시각언어를 통한 의미전달수단 모두를 총체적으로 의미하는 것이라 하였다. 본 연구에서 내러티브 페이 퍼크라프트 패션은 자연 인간 동물의 형상을 스토리 로 서술하여 시각적으로 재현한 것으로 토속적 민속 적 표현까지 이 영역에 포함시켰다.

분석결과, 내러티브 페이퍼크라프트 패션은 동식 물 형태를 동화적 스토리로 재현하거나, 자연이나 생 활환경의 사실적 묘사, 민속적 요소들을 인체에 접목 한 환상적인 작품이 많이 나타났다. 표현방식은 오리 가미와 자르기 기법으로 구체적인 사실을 가진 장면 이나 대상을 표현하였다.

〈Fig. 12〉는 폴란드에 태어나 스웨덴에 활동하고 있는 디자이너 Bea Szenfeld가 2003년 발표했던 '해 변에서(Sur la Plage)'테마의 컬렉션 작품들 중 하나 이다. 이 콜렉션은 세일러 포클로어(sailor folklore), 치명적인 독이 있는 복어(puffer fishes)와 매혹적인 바다 요정에서 영감을 얻었으며, 자르기과 폴딩 기법 으로 12 개의 놀라운 상상속의 작품들을 동화적 스토 리로 내러티브 되었다. 이 작품은 은은하게 반짝거리 는 핑크 메탈릭 이미지의 오뜨 페이퍼 (haute peppier) 재킷이다(Bea Szenfeld, 2010). 삼차원의 페이퍼크라 
프트의 폴딩 기법으로 풍선처럼 부풀고 있는 복어 이 미지를 재현하고 있다.

〈Fig. 13〉은 호주에서 활동하고 있는 일러스트레이 터이자 디자이너인 Stuart Mclachlan이 2008년 발표 한 작품이다. 그의 작품은 집이나 배와 같은 조형물 을 비롯하여 새, 나비, 사람, 나무와 같은 자연 생물 등 인간생활 주변의 것들에서 모티브를 얻어 동화적 인 스토리를 섬세하게 묘사하고 있다.

〈Fig. 14〉는 디자이너 Bea Szenfeld가 2014년에 발 표했던 'Haute Papier' 작품이다. 이 컬렉션의 가장 큰 특징은 동물과 식물 이미지 형태를 구현하는 것이 었다. 종이 자르기와 접기 등의 기법을 사용해 테디 베어, 코끼리, 사자 등 동화적 캐릭터를 예술적 의상 으로 표현하여 상상을 초월한 디자인을 선보였다. 이 작품은 사자캐릭터를 작품화한 것이다.

〈Fig. 15〉는 우크라이나 아티스트 Asya Kozina가 2014년 몽골족 옷 스타일과 민족정서를 묘사한 작품 이다. 풍부한 상상력으로 몽골의 민속적 디테일을 서 구적 드레스와 머리장식으로 접목하여 작가가 전달 하고자하는 환상적 이미지를 표현하였다.

\section{2) Organic papercraft fashion}

오가닉 디자인의 궁극적인 미적 가치는 순수미와 조형구조에 따른 균제미라 할 수 있고, 그것은 의도적 이거나 의식적으로 만들어지는 것이 아니라, 자연스

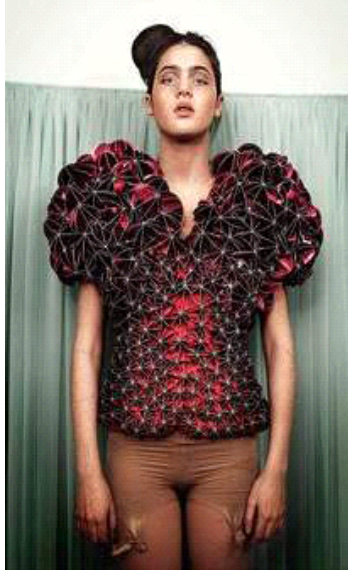

<Fig. 12> Bea Szenfeld, 2003. From. Bea Szenfeld. (n.d.b).

http://www.szenfeld.com

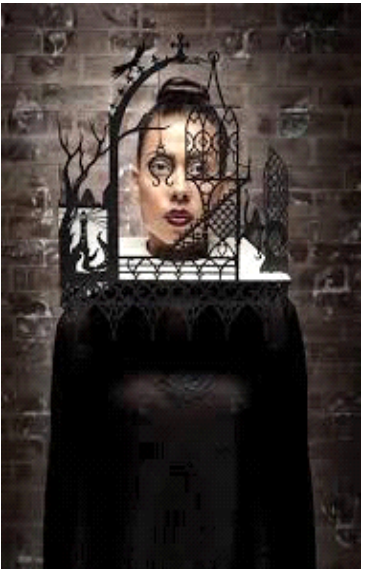

<Fig. 13> Stuart Mclachlan, 2008. From. Stuart Mclachlan. (n.d.). http://www.stuart-mclachlan.com

러운 물리적 현상에 의해 만들어진 질서라고 정의를 내 릴 수 있다. 패션에서는 에콜로지 패션(ecology fashion) 과 같은 뜻으로 사용되거나, 천연소재 지향, 유기농에 대한 관심, 표백 염색하지 않은 에크루(écru)나 베이 지와 같은 색채, 지나치게 손질을 하지 않은 민족복, 내추럴 의상이나 여유있는 실루엣을 담은 스타일을 말한다.

본 연구에서의 오가닉 페이퍼크라프트 패션은 자 연 원리에 따라 자연형상을 순수하게 표현하고자하 는 유기적 형태의 패션으로 범주화하였다. 오가닉 페 이퍼크라프트 패션 사례분석에서는 자연적 형상을 유 기적인 선으로 단순화하여 배치하거나 반복된 자연 물의 균등한 패턴에서 나타나는 아름다움을 조형적 인 패션디자인으로 표현하였다.

〈Fig. 16〉은 디자이너 Alexandra Zaharova와 Ilya Plotnikov가 2009년 L'Officiel 잡지에 발표된 페이퍼 크라프트를 활용한 패션디자인 작품이다. 한 장의 종 이로 인체를 감싸면서 드러나는 유기적인 선은 오가 닉 구조를 표현하고 있다(7CIRCLE, 2011).

〈Fig. 17〉은 디자이너 Amila Hrustic이 2010년 발표 했던 작품 'Plato's Collection'중 한 작품이다. 이 컬 렉션은 플라톤 철학에서 비롯된 5 개의 고체(정사면 체, 정육면체 정팔면체, 정십이면체, 정이십면체)에서 영감을 얻어 진행되었다. 이 작품은 비정형의 정육면 체들을 인체의 형태에 따라 유기적으로 반복 배열한

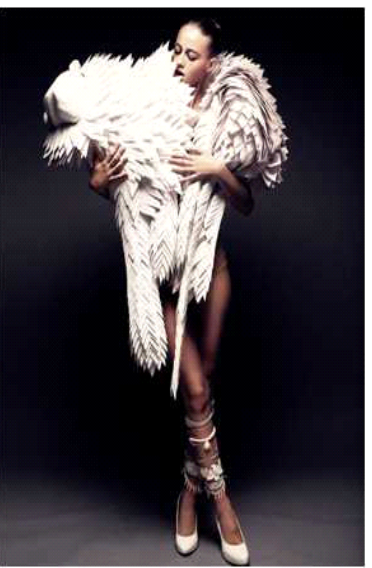

<Fig. 14> BBea Szenfeld, 2014. From. Bea Szenfeld. (n.d.a).

http://www.szenfeld.com

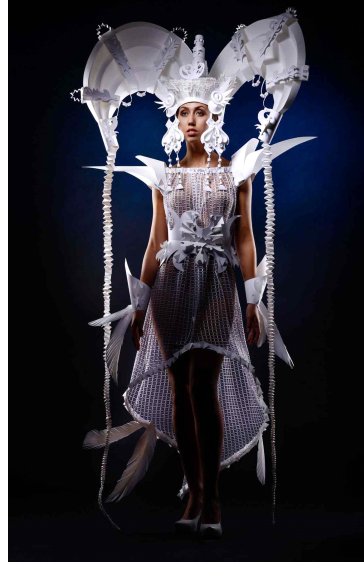

$<$ Fig. 15> Asya Kozina, 2014. From. Kozina. (n.d.). http://www.behance.net 
오가닉 구조의 페이퍼크라프트 드레스이다(Warmann, 2010).

〈Fig. 18〉은 영국의 페이퍼크라프트 아티스트인 Polly Verity가 2001년에 발표했던 작품이다. 이 작품은 곡 선과 직선으로 이루어진 사면체 또는 오리가미로 접 어진 원형의 입체들을 연결하여 순수한 오가닉의 페 이퍼크라프트 패션작품을 표현한 것이다.

〈Fig. 19〉는 미국에서 활동하는 아티스트 Diana Gamboa가 2013년에 발표했던 작품으로 하나의 종이를 오 리가미 기법으로 접어 반복적으로 생기는 유기적인 패 턴으로 이루어진 입체감은 순수미를 표방하고 있다.

\section{3) Variable papercraft fashion}

현대 패션디자인에서 가변적인 디자인 창작은 전 위성과 예술성이 가진 작가의 창조적인 디자인 감성 을 표현하고자 새로운 기법이나 표현방식을 시도하 는 과정이라 볼 수 있다. 본 연구의 분석결과, 가변적 페이퍼크라프트 패션은 하나의 아이템이 다양한 구 조로의 전환되거나 착용자의 신체동작에 따라 형태 가 변화되거나 착용방법에 따라 디자인이 변화하는 것으로 나타났다.

〈Fig. 20〉은 2009년 이탈리아의 디자인 스튜디오 GAIA design에 의한 제작된 것이다. 'Veasyble'의 제 목으로 진행된 프로젝트는 디자이너 Gloria Pizzilli, Arianna Petrakis, Ilaria Pacini, Adele Bacci가 참여하 였다. 4명이 각각 고립, 친밀, 폭로, 장식이라는 4가지



<Fig. 20> GAIA design, 2009. From. Veasyble. (n.d.). http://www.veasyble.com

개념에서 출발하여 종이와 폴리에틸렌 패브릭을 이 용해 공동 제작한 것이다. 이것은 현대의 복잡한 사 회생활 속에 인간의 연약함을 보호하고, 이동이 많은 생활환경에서 휴대 간편하고 변형 가능한 옷을 제안 한 것이었다. 착용자는 아코디언처럼 접고 펼칠 수 있는 옷으로 어떤 장소에서든지 자신만의 친밀한 공 간을 만들어 안락함을 유지한다는 것이다.

〈Fig. 21〉은 헝가리 패션디자이너 Dora Kelemen 2010년에 ‘Angel'을 주제로 발표했던 작품이며, 접기 기법으로 가변적 형태를 가능하게 해 실제로 입을 수 있는 종이옷을 구현하였다. 어깨를 펼치면 천사의 날 개처럼 보이고, 팔을 내리면 그냥 옷 같으며, 유동성을 가지고 있는 웨어러블(wearable) 페이퍼 패션디자인

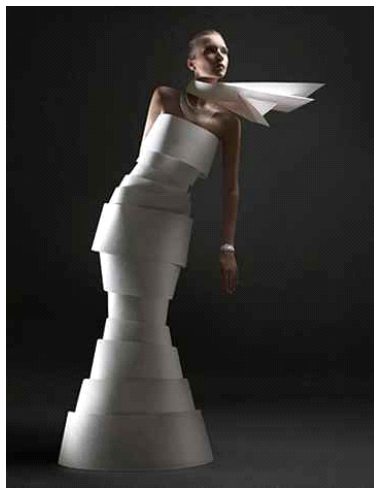

<Fig. 16> Alexandra \& Ilya, 2009. From. 7CIRCLE. (2011). http://mix-magazines. blogspot.kr

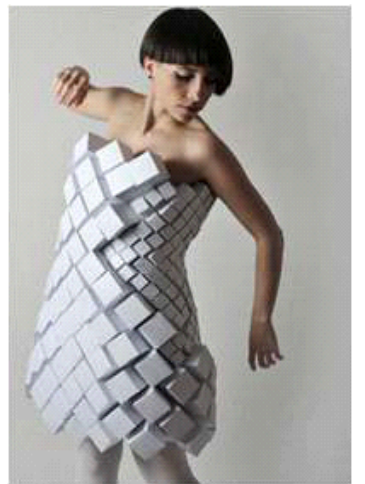

<Fig. 17> Amila Hrustic, 2010. From. Warmann. (2010)

https://www.dezeen.com

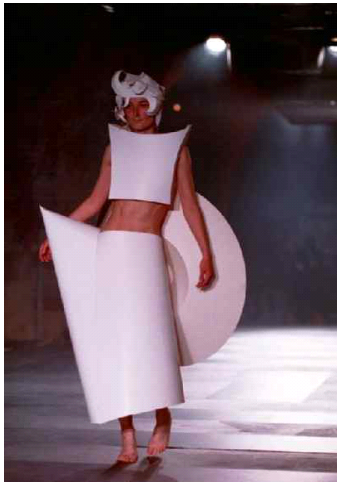

<Fig. 18> Polly Verity, 2001. From. Malik. (2011). http://the-usa-breakingnews.blogspot.kr

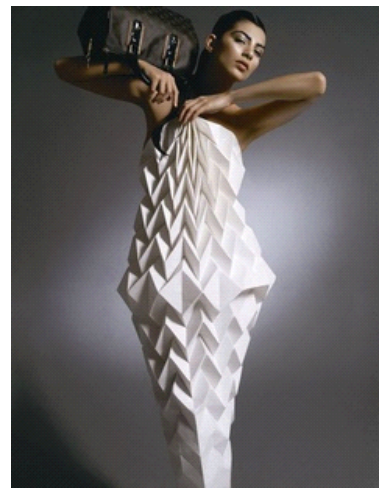

<Fig. 19> Diana Gamboa, 2013. From. Abitiscultura. (2013). https://abitiscultura. wordpress.com 


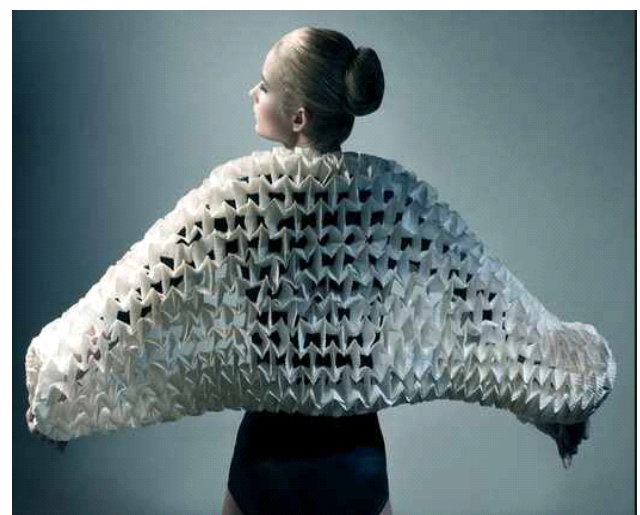

<Fig. 21> Dora Kelemen, 2010. From. Jasmine. (2010). http://strictlypaper.com

의 대표적인 작품이라고 할 수 있다.

〈Fig. 22〉는 Mauricio Velasquez Posada 2010년 작 품이며, 페이퍼크라프트 팝업기법을 사용하였다. 소 매와 드레스 사이의 공간에 접고 펼칠 수 있는 조형 적 형태를 배치하여 팔의 움직임 상태에 따라 드레스 의 디자인이 다양하게 변하는 가변성을 가진 창의적 인 디자인이다.

〈Fig. 23〉은 쥘 와벨(Jule Waibel)이 2013년 제작한 작품으로 옷과 장신구 모두 가변적인 형태이다. 독일 어로 '펼치기'를 의미하는' Entfaltung'이라는 제목의 프로젝트로 가볍고 찢어지지 않는 합성 종이 타이벡 (Tyvek)을 사용하였다. 아코디언 구조로 접고 펼치는 것을 가능하게 한 노란색 드레스, 녹색 가방, 주황색 우산을 특징으로 하고 있다.

\section{4) Recycling papercraft fashion}

패션디자인에서의 리사이클은 그린디자인의 중요 성이 강조된 이래 다양한 트렌드와 맞물려 지속적으 로 등장하고 있다. 종이는 천연소재로 인간의 일상적 인 생활에서 다채로운 용도로 필수적으로 사용되고 있으며, 버려지는 종이는 패션디자인분야에서도 활용 되고 있다. 이전의 사용 흔적이 디자이너의 콘셉으로 의미를 되찾거나, 자원재활용의 가치를 지니며 수공 예적 표현방법으로 재탄생되는 것이다.

본 연구의 사례분석 결과, 리사이클링 페이퍼크라 프트를 활용한 패션 디자인들은 시간이 지난 신문, 오래된 종이 지도, 버려진 크라프트지를 재생하여 사 용했으며, 자원재생의 의미와 함께 종이 재생과정의 스토리를 컨셉에 활용한 것들이 나타났다.

〈Fig. 24〉는 벨기에 예술가인 이사벨 드 보흐그레이 브 (Isabelle de Borchgrave)가 2007년에 발표했던 작 품이며, 래그 페이퍼(rag paper)로 제작되었다. 래그 페이퍼는 넝마를 원료로 만드는 고급용지로 Borchgrave는 래그 페이퍼를 염색하여 그 위에 그림을 그 려서 독창적인 페이퍼크라프트 패션디자인을 창조하 였다. 이 작품은 화가 Agnolo Bronzino(1503 1572) 의 그림 중 인물의 옷 스타일을 페이퍼크라프트를 통 해 재현한 것이다. 종이로 만든 작품위에 트롱프뢰유 (trompe-l'œil)기법으로 그림을 그려 실물 작품처럼 정 교한 드레스를 만들었다(Isabelle de Borchgrave, n.d.a).

〈Fig. 25〉는 미국 아티스트 Jolis Paons가 2008년 발표한 오래 된 전화번호부로 만든 고급스러움을 지 향하는 드레스이다. 전화번호부를 한 페이지씩 섬세

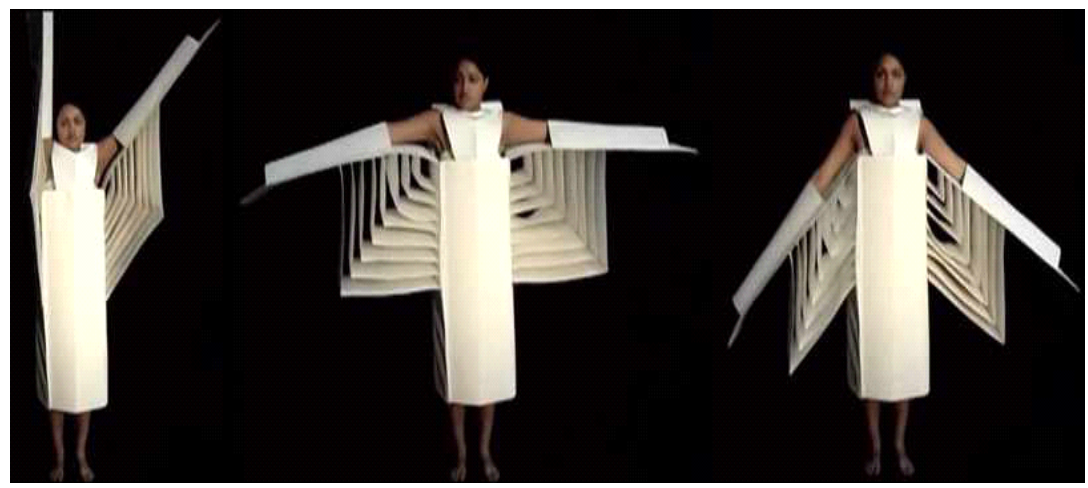

<Fig. 22> Mauricio Velasquez Posada, 2010. From. Velasquez. (2010). http://www.youtube.com

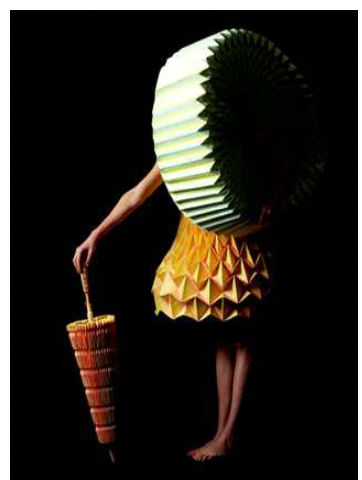

<Fig. 23> Jule Waibel, 2013. From. Waibel. (2013). http://www.julewaibel.com 
하게 접고 구기고 부쳐서 오뜨 페이퍼 드레스를 창조 하였다.

〈Fig. 26〉은 우크라이나에서 태어나 현재는 영국 런던에서 활동하고 있는 패션디자이너 Yuliya Kyrpo 가 2010년 런던과학박물관 쓰레기 패션전시회(Trash Fashion exhibition)'에 출품했던 작품이다. 이것은 신 문지를 접어 만든 수많은 종이 접기 학으로 긴 트레 인이 달린 독특하고 복잡한 모양의 이브닝 드레스로 만들어진 것이다(Lam, 2010).

〈Fig. 27〉은 영국 런던에 살고 있는 아티스트 Elisabeth Lecourt에 의해 제작된 작품이다. 작가는 주로 국 가나 도시의 오래된 종이 지도를 페이퍼크라프트 드 레스의 소재로 사용하고 있는데, 이 작품은 1932년도 발행된 Losangeles 파노라마 관광지도로 만들어진 것 이다(Elisabeth Lecourt, 2012).

\section{Expressional characteristics of papercraft fashion}

〈Fig. 28〉은 페이퍼크라프트 패션 유형별로 관련된 예술 디자인 분야 페이퍼크라프트 표현특성과 페이 퍼크라프트 패션표현 특징 그리고 페이퍼크라프트 패션표현특성을 정리한 것이다. 첫째, 내러티브 페이 퍼크라프트 패션은 예술디자인분야의 페이퍼크라프 트 사례고찰에서 나타난 '스토리텔링' 특성과 관련하 여 분류된 것으로 동식물 형태의 동화적 스토리 표 현, 자연적 환경의 사실적 묘사, 민속 공예품을 도입

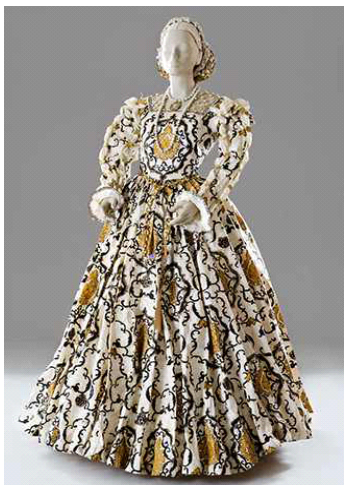

<Fig. 24> Isabelle de Borchgrave, 2007. From Isabelle de Borchgrave. (n.d.b).

http://www.isabelledeborc

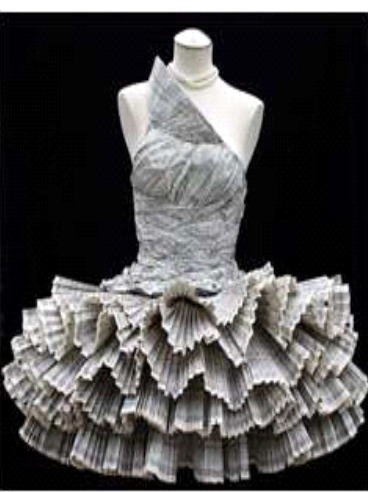

<Fig. 25> Jolis Paons, 2008. From. Mediterranean. (2008). http://www.trendhunter.com
한 민족정서의 디자인 컨셉화 등의 표현 특징으로 나 타났다. 표현특성은 ‘환상적', ‘유희적', '인간 친화적', '고부가가치' 특성과 관련되었다.

둘째, 오가닉 페이퍼크라프트 패션은 예술디자인 분야의 페이퍼크라프트 특성인 '오가닉'과 관련되어 분류되었고, 자연적 형상을 단순화시킨 유기적인 연 속선의 표현과 자연물에서 발견한 균일한 패턴을 활 용한 유기적 형태표현의 특징으로 나타났다. 표현특 성은 '고부가가치'와 '미래지향적' 특성과 관련되었 다.

셋째, 가변적 페이퍼크라프트 패션은 예술디자인 분야의 페이퍼크라프트 특성 '가변성'과 관련되어 분 류되었고, 패션의 표현특징은 다양한 구조로 변화하는 하나의 옷, 의복 착용자의 제스츄어에 변화하는 옷의 형태, 착용방법에 따른 옷 디자인의 변화 등으로 나 타났다. 표현특성은 ‘유희적', ‘고부가가치'와 '미래지 향적' 특성과 관련되었다.

넷째, 리사이클링 페이퍼크라프트패션은 예술디자 인분야의 페이퍼크라프트 특성인 '리사이클링'과 관 련되어 분류되었고, 버려진 신문, 전화번호부, 오래된 종이지도 등 지난 종이재료들을 재생하여 사용과 빈 티지 종이들이 가진 역사적이거나 일상적인 스토리 를 디자인 컨셉으로 활용한 것이 표현특징으로 나타 났다. 표현특성은 '환상적', ‘유희적', ‘고부가가치' 특 성과 관련되었다. hgrave.com

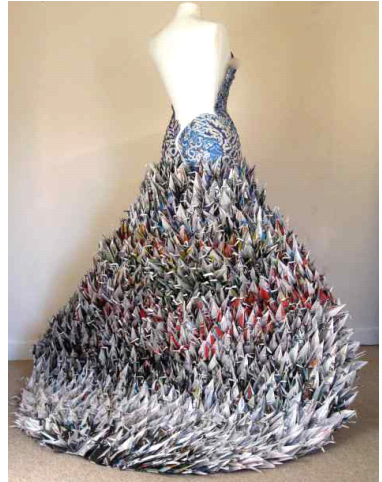

<Fig. 26> Yuliya Kyrpo, 2010. From. Lam. (2010). http://www.trendhunter.com Elisabeth Lecourt. (2012). http://www.elisabethlecourt .com 


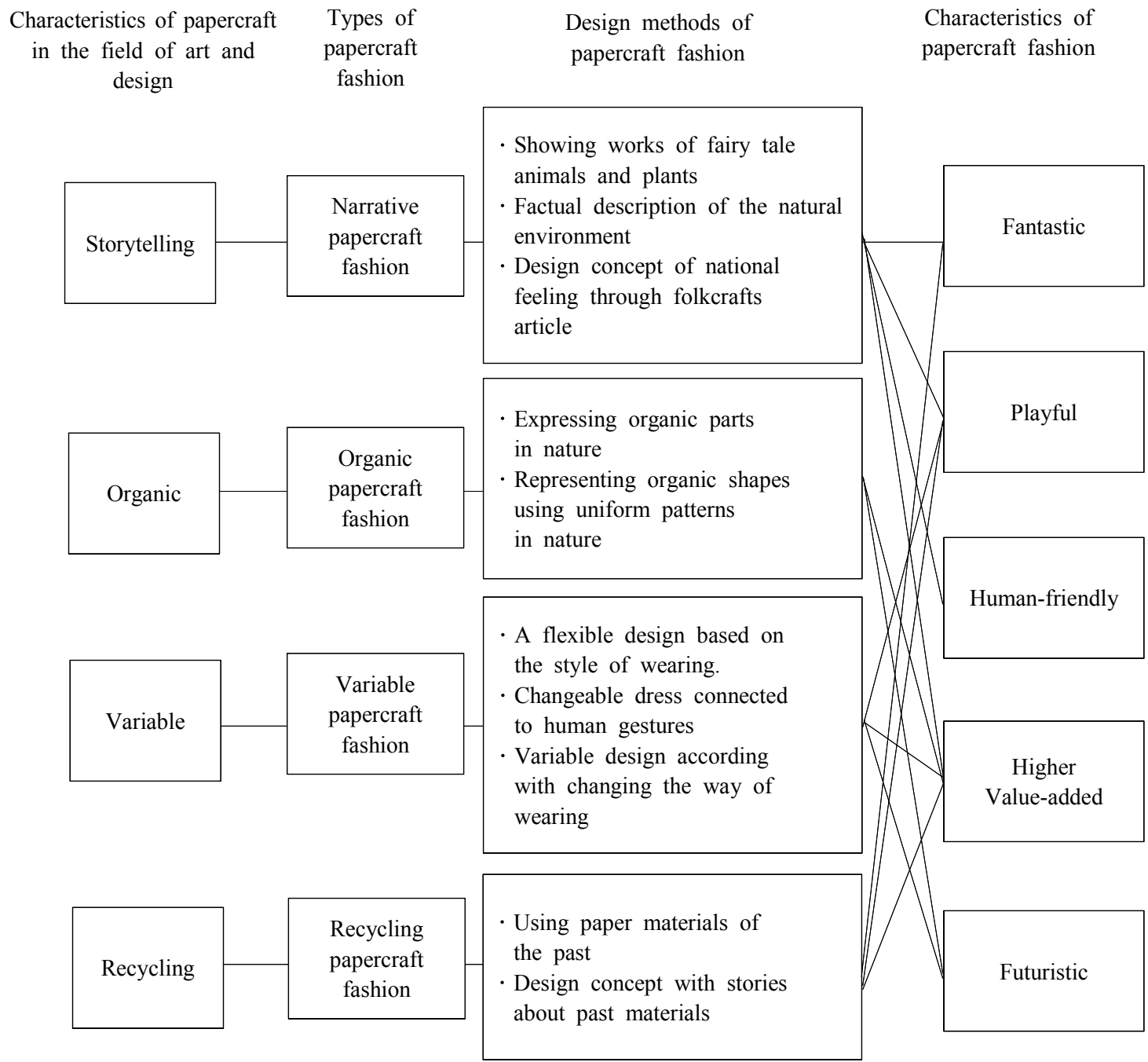

<Fig. 28> Expressional characteristics of papercraft fashion

\section{Conclusion}

본 연구에서는 인간 친화적인 특성과 차별화 된 예 술성으로 다양한 디자인 분야에서 주목받고 있는 페 이퍼크라프트의 예술적 특성과 표현특징이 패션에서 어떻게 표현되고 있는지 밝히고자 하였다. 페이퍼크 라프트로 제작된 작품들은 종이가 가지는 손으로 직 접 만든다는 수공예 가치와 종이소재의 질기면서도 연약한 물성과 내재된 이미지, 자연소재로서의 환경 적 가치, 이미 사용한 종이소재의 재활용성 등이 디 자이너의 콘셉으로 활용되어 제작되었다. 패션 사례
분석결과, '내러티브 페이퍼크라프트 ', ‘오가닉 페이 퍼 크라프트', '가변적 페이퍼크라프트', ‘리사이클링 페이퍼 크라프트’로 유형을 분류할 수 있었다. 결과 적으로 각 유형별 디자인 방법과 표현 특성은 다음과 같이 정리되었다.

첫째, 내러티브 페이퍼크라프트 패션에서는 동화 적으로 캐릭터화된 동 - 식물 형태를 오리가미나 페 이퍼커트기법으로 환상적으로 재현하면서 유쾌한 메 시지를 전달하였다. 둘째, 오가닉 페이퍼크라프트 패 션은 유기적으로 표현된 자연 형상을 적용한 미래적 인 패션으로 표현하거나, 자연물의 균일한 패턴을 재 
배치하여 유기적 오뜨 페이퍼크라프트 패션을 표현 하였다. 셋째, 가변적 페이퍼크라프트 패션은 구조변 화나 착용자의 움직임으로 변화가능한 가변적인 옷 으로 즐거움을 주는 고급스러운 페이퍼크라프트패션 으로 표현되었다. 넷째, 리사이클링 페이퍼크라프트패 션은 버려진 종이재료들을 재생하여 빈티지 재료들 이 가지고 있는 역사나 일상적 스토리를 컨셉화함으 로써 환상적인 페이프크라프트 패션으로 승화하였다.

이상의 결과는 디지털시대 인간친화적인 소재로의 종이활용으로 아날로그감성의 패션디자인 창출과 차 별화된 디자인을 창조하고자하는 패션디자이너에게 디자인 소스로 제공되어 고부가가치 패션 디자인 개 발에 도움이 되고, 페이퍼크라프트 연구의 기초적 자 료로 활용되기를 기대한다. 단, 본 연구가 페이퍼 크 라프트 패션의 개념적 표현방법을 중심으로 이루어 지면서 미처 다루지 못한 페이퍼 크라프트의 기법과 페이퍼크라프트 패션유형에 따른 양적 분석결과는 후속연구로 다루고자 한다.

\section{References}

7CIRCLE. (2011, February 14). Paper dresses by Alexandra Zaharova \& Ilya Plotnikov [Blog post]. Retrieved October 20, 2015, from http://mix-magazines.blogspot.kr/2011/02/paper-dresses-by-alexan dra-zaharova.html

Abitiscultura. (2013, June 12). Diana Gamboa [Blog Post]. Retrieved October 20, 2015, from https://abitiscultura.wordpress.com/2013/06/12/diana-gamboa

Akira Yoshizawa is the Grandmaster of Origami. (2016, March 10). Barnorama, Retrieved March 15, 2016, from http:/www.barnorama.com/akirayoshizawa-is-the-grandmaster-of-origami

Bea Szenfeld. (2010, April 9). Sur La Plage. Retrieved October 20, 2015, from http://www.szenfeld.com/ sur-la-plage

Bea Szenfeld. (n.d.a). Haute Papier. Retrieved October 20, 2015, from http://www.szenfeld.com/collections/haute-papier

Bea Szenfeld. (n.d.b). Sur La Plage. Retrieved October 20, 2015, from http://www.szenfeld.com/collec- tions/sur-la-plage

Brian Dettmer. (2010). Wagnalls wheel. Retrieved October 11, 2015, from http://briandettmer.com/ art/2010/\#p938

Bumpus, J. (2011, March 4). Issey Miyake: Autumn/ Winter 2011 Ready-to-wear. Vogue, Retrieved October 11, 2015, from http://www.vogue.co.uk/ shows/autumn-winter-2011-ready-to-wear/issey-m iyake

Elisabeth Lecourt. (2012). Les robes géographiques. Retrieved October 20, 2015, from http://www.elisabethlecourt.com/works/les-robes-geographiques

Honey-Pop chair. (n.d.) Victoria and Albert Museum, Retrieved October 11, 2015, from http://collections.vam.ac.uk/item/O113420/honey-pop-chair-c hair-yoshioka-tokujin

Isabelle de Borchgrave. (n.d.a). Biography. Retrieved October 20, 2015, from http://www.isabelledeborchgrave.com/en_bio.php

Isabelle de Borchgrave. (n.d.b). Éléonore de Tolède, 1522-1562. Retrieved October 20, 2015, from http://www.isabelledeborchgrave.com/en_creation s.php?nav_link $=01 \&$ nav2_link $=02 \&$ classement $=02$ Jasmine. (2010, August 18). Dora Kelemen: Angel [Blog Post]. Retrieved October 20, 2015, from http://strictlypaper.com/blog/2010/08/dora-keleme n-angel

Jeff Nishinaka Paper Sculpture. (n.d.a). About. Retrieved October 11, 2015, from http://www.jeffnishinaka. com/about

Jeff Nishinaka Paper Sculpture. (n.d.b). Fine Art. Retrieved October 11, 2015, from http://www.jeffnishinaka.com/wea5jz14a6g5xaqgppvg4xolu3dg21

Jung, Y. J. (2004). A study of formativeness expressed in Korean-paper fashion design. Journal of Korean Fashion \& Costume Design Association, 6(2), 103-109.

Kang, B.-K. (2008). A study of organic form applied in design. The Treatise on The Plastic Media, 11(1), 3-8

Kim, K. H. (2005). A study of design for modern 
leather fashion: Focused on the design applied to paper-modeling method. Unpublished master's thesis, Hongik University, Seoul, Korea.

Klanten, R., \& Meyer, B. (2011). Papercraft 2: Design and art with paper. Berlin: Gestalten.

Kozina, A. (n.d.). Mongolian costumes. Retrieved October 20, 2015, from https://www.behance.net/ gallery/21079875/mongolian-costumes

Lam, J. (2010, July 20). Paper crane frocks: The Yuliya Kyrpo upcycled origami dress is made of reused newspapers. Trend Hunter, Retrieved October 20, 2015, from http://www.trendhunter.com/ trends/yuliya-kyrpo

Malik. (2011, August 12). Fashion show dresses [Blog Post]. Retrieved October 20, 2015, from http://the-usa-breaking-news.blogspot.kr/2011/08/f ashion-show-dresses.html

Mediterranean. (2008, July 8). Dresses made from phonebooks: The paper dress by Jolis Paons. Trend Hunter, Retrieved October 20, 2015, from https:// www.trendhunter.com/trends/paper-dress

Nendo. (2008, March). Cabbage chair. Retrieved October 11, 2015, from http://www.nendo.jp/en/works/ cabbage-chair-2

Nomidou, V. (2010, February 20). Photos [Blog post]. Retrieved October 11, 2015, from https://vallynomidou.wordpress.com/2010/02/20/photos

Ong, J. (2011, August 11). Rebecca Wilson ceramic paper cups. Neatorama, Retrieved October 11, 2015, from http://www.neatorama.com/2011/08/11/ rebecca-wilson-ceramic-paper-cups

Paper clothing. (n.d.). In Wikipedia. Retrieved October 11, 2015, from https://en.wikipedia.org/wiki/ Paper_clothing

Paper craft. (n.d.). In Wikipedia. Retrieved October 2, 2015, from https://en.wikipedia.org/wiki/Paper_craft Richard Sweeney. (n.d.). Selfridges. Retrieved October 11, 2015, from http://www.richardsweeney. co.uk/selfridges

Ryu, S. (2007). Characteristics of modeling shown from paper materials in modern art. Unpublished master's thesis, Chosun University, Gwangju, Korea.

Ryuji Nakamura. (n.d.). Hechima 5. Retrieved October 11, 2015, from http://www.ryujinakamura. com/z_material/work/hechima_5/00.html

Second Nature. (n.d.). Hechima 5. Rundetaarn, Retrieved October 11, 2015, from http://www.rundetaarn.dk/engelsk/09second.html

Stuart Mclachlan. (n.d.). Wearable paper gallery. Retrieved October 20, 2015, from http://www.stuartmclachlan.com/new-gallery/fea36lplwm4epqzrsze w48b40ebahe

Tsikouta-Deimezi, L. (2011, January 16). The vulnerable- strong figures by Vally Nomidou [Blog post]. Retrieved October 11, 2015, from https://vallynomidou.wordpress.com/2011/01/16/28

Veasyble. (n.d.). Project. Retrieved October 20, 2015, from http://www.veasyble.com/project.html

Velasquez, M. (2010, August 8). Animorfos.mpg [Video file]. Retrieved October 20, 2015, from https:// www.youtube.com/watch?v=7bBtMA2 $\mathrm{miHc}$

Waibel, J. (2013, June). Entfaltung: Unfold, expand, develop. Retrieved October 20, 2015, from http:// www.julewaibel.com/Entfaltung-Unfolded-paperdresses

Warmann, C. (2010, November 23). Plato's collection by Amila Hrustić. Dezeen, Retrieved October 20, 2015, from https:/www.dezeen.com/2010/11/23/ platos-collection-by-amila-hrustic

Yifan. (2013, December 2). 李闽的新写实剪纸 [Leemin's new realistic paper-cut] [Blog Post]. Retrieved October 11, 2015, from http://blog.sina.com. $\mathrm{cn} / \mathrm{s} / \mathrm{blog}$ a5120d5b0101o7mo.html

Yuko Nishimura. (n.d.). Works. Retrieved October 11, 2015, from http://yukonishimura.com/works-en.php Yun, Y., \& Yang, S.-H. (2004). Visual narrative technique in modern fashion photography: Focusing on Philip-Lorca diCorcia's Stranger in Paradise. The Research Journal of the Costume Culture, 12(6), 918-932. 